talented Arab students with the opportunity to pursue U.S. study. Please direct donations to: Diana Kamal Scholarship Fund-AMIDEAST, 1730 M St., N.W., Suite 1100 , Washington, DC 20036.

Betsy Laun Maalouf AMIDEAST

\title{
Evelyn Abdalah Menconi (1919-2003)
}

All of her life, Dr. Evelyn Abdalah Menconi loved the Arab-American community of the greater Boston area. She was born and grew up in West Roxbury and attended Boston University. A consummate educator, Dr. Menconi served as teacher/principal at the USAF Dependents Schools in France and Japan, was a teacher and reading consultant in the Boston Public Schools from 1940 to 1979 , and continued her role as an educational consultant and media specialist throughout her life.

Evelyn and her husband Armand lived in Dorchester and together had a rich life surrounded by family and friends. In 1981, she earned her doctorate in education from Boston University. Her dissertation, "An Analysis of Teachers' Perceptions of the Arab World," demonstrated her commitment to promoting understanding of Arab-American culture. She dedicated the work to her parents, Nazirah Haboush and George Abdalah, who emigrated from Syria as teenagers and who "understood the importance of building bridges between east and west."

Dr. Menconi promoted Arab-American culture through the founding of the William G. Abdalah Library, established in her brother's memory, and served as an educational consultant to "The Arabic Hour" television program. She collaborated in the publication of many cookbooks including Arabic Cooking in America (1977), together with Yvonne Homsy and Mary Maloof. She wrote articles for numerous publications including Middle East Resources where her article, "Arabs in the Boston Area," was published in May of 2000. As she said to family and friends, "This is my story!"

For many years, Evelyn was an avid collector of informational materials for use in educational programs, and shared them with other groups. As she said, "It is a wonderful way to show that we Arab-Americans have inherited a warm and beautiful culture and that the Arabs have made many worthwhile contributions to Western Civilization in the applied arts as well as the fine arts, the sciences and literature."

Dr. Menconi was active in many organizations, including the Dorchester Historical Society, the Lebanese-Syrian Ladies Aid Society, the Syrian-Lebanese Women's Club of Greater Boston, the American Arabic Association, the Nicholas G. Beram Veterans Ladies Auxiliary, and Maloof International. She has received many awards for her service to the Arab-American community.

Evelyn Abdalah Menconi will be remembered as a woman of deep compassion, generosity, love and humility. Her greatest joy was to gather friends and family together for wonderful Arabic food, good conversation, laughter and fun. She was a treasure to all who knew her. Her life-long mission of promoting peace and social justice for all people is a part of her enduring legacy.

Elissa Menconi 